Article

\title{
Investigations on the Influence of Chemical Compounds on Fog Microphysical Parameters
}

\author{
Ognyan Ivanov ${ }^{1, *}$, Petar Todorov $^{1}$ and Ismail Gultepe T, $^{\text {(D) }}$ \\ 1 Georgi Nadjakov Institute of Solid State Physics, Bulgarian Academy of Sciences, \\ 72 Tzarigradsko Chaussee Blvd., 1784 Sofia, Bulgaria; pv_todorov@abv.bg \\ 2 Meteorological Research Division, Environment and Climate Change Canada, Toronto, ON M3H5T4, \\ Canada; ismail.gultepe@canada.ca \\ 3 Faculty of Engineering and Applied Science, Ontario Tech University, Oshawa, ON L1G0C5, Canada \\ * Correspondence: ogi124@yahoo.com
}

Received: 19 January 2020; Accepted: 24 February 2020; Published: 26 February 2020

\begin{abstract}
Lab experiments related to artificial fog studies are limited due to instrument sensitivity to small fog and aerosol particles; therefore, the goal of this work is to evaluate aerosol solute effects on fog physical properties in a lab environment. To reach the goal, an automated fog-generating system was designed and that includes controlled chemical compounds dissolved in pure water. In the analysis, the impact of changing the mass concentration of potassium dihydrogen phosphate- $-\mathrm{KH}_{2} \mathrm{PO}_{4}$, urea-CO $\left(\mathrm{NH}_{2}\right)_{2}$, and potassium hexacyanoferrate trihydrate- $\mathrm{K}_{3}\left(\mathrm{Fe}(\mathrm{CN})_{6}\right)$ on fog droplet size spectra is studied, because visibility is directly related to fog droplet spectra and aerosol composition. In the experiment, various microphysical conditions, including fog droplet size and volume concentration, were analyzed as a function of changing aerosol composition/spectra and fixed thermodynamic conditions. The results showed that fog droplet size spectra vary with the addition of chemical impurities to the pure water volume. For example, increasing $\mathrm{KH}_{2} \mathrm{PO}_{4}$ concentration compared to distilled water volume resulted in a higher mean particle size, which led to faster droplet settlement, and that resulted in cleaning air more efficiently compared to pure water fog. Overall, both issues and challenges of the experimental fog generating system with respect to water and aerosol solutions resembling CRBN (chemical, radiological, biological, and nuclear agents) characteristics are provided and evaluated.
\end{abstract}

Keywords: fog; visibility; physical parameters; chemical compounds; aerosols

\section{Introduction}

The impact of aerosols on the fog removal process occurring in lab environments can be applicable to real environmental conditions. Physical and chemical properties of aerosols affect droplet formation and size spectra, which are dependent on thermodynamical and dynamical conditions. Fog can be a natural or artificial phenomenon that has been studied extensively in the past [1]. It affects visibility [2,3], air quality, climate, agriculture [4], human health [5], firefighting, and transportation [2,6,7]. Microphysical parameters of fog can be highly variable and need to be further studied using observations and prediction models [1,8]. Furthermore, artificially produced fog types can also be studied for similar applications [6,7], plus applications to industrial processes. Fog with suitable additives has been also used as a cleaning agent of chemical species generated by the military or terrorist actions, aviation accidents, or natural disasters.

In order to obtain a better understanding of fog prediction, earlier works have extensively studied natural fog with respect to its formation and dissipation processes. Both fog and rain can act as natural "cleaners" of the lower atmosphere, because they wash out various aerosol particles as they fall into the 
Earth's surface, and that includes nuclei [9]. Due to its nature, the present work is closely connected to fog formation, dissipation, and nucleation issues occurring in the lab and in the real atmosphere.

The idea of using fog generation as an air-cleaning agent is important to develop new technologies; therefore, a project called COUNTERFOG was initiated. The main purpose of this project is to develop a fog dissipation system to reduce adverse effects of social unrest dealing with CBRN (chemical, biological, radiological, and nuclear) agents; industrial accidents; and disasters. This system uses specially developed devices and parts with novel nozzles for the generation of fog with additives, which neutralizes harmful substances within the air and deposits them on the ground [10]. An important step for control of the presence and the concentration of chemical compounds (considered impurities) in artificially generated fog is to develop a sensor system. The current sensor [11] used in this work is developed based on results grouped under the working name "surface photo-charge effect" (SPCE). This effect is quantified when there is an interaction between matter (gas, liquid, or solid) and an electromagnetic field. This interaction induces an electrical alternating potential difference over the frequency field [12]. Ivanov [13] observed the effect and suggested the name of the effect to be changed to "electromagnetic echo effect" (EMEE), since this result better reflects the nature of the effect. This way, it is not being confused with the photoelectric effect. The current work uses an EMEE sensor in a development of the cleaning properties of fog.

Many experimental investigations were performed in the past to better evaluate how various types of aerosol impurities influence the physical parameters of artificially generated fog. An automated fog generating system (AFGS) suitable for performing such tests has been developed [14,15]. This AFGS is used to focus on how added chemicals affect the microphysical parameters of artificially generated fog. To do this, varying concentrations of harmless chemical compounds were dissolved in distilled water for simulation of real CBRN agents. These agents, replaced with harmless chemicals, were then pulverized using a newly developed automated system in which fog droplets were generated and measured by a laser particle size analyzer. The results were analyzed to identify the influence of chemical compounds on fog parameters, such as particle spectra, leading to changes in droplet number concentration $\left(\mathrm{N}_{\mathrm{d}}\right)$ and liquid water content (LWC), as well as mean volume diameter (MVD).

The goal of this work is to study fog microphysical parameters, such as droplet volume concentration $\left(\mathrm{V}_{\mathrm{d}}\right)$ and $\mathrm{MVD}$, as a function of chemical compounds dissolved in distilled water, and for this purpose, the EMEE system was used for investigations. Then, the chemical processes taking place for the alteration of fog spectral characteristics are reviewed. This work is designed as follows: Section 2 focuses on experimental setup, and Sections 3 and 4 are for the Results and Discussion, respectively. The last section (Section 5) is given for the Conclusions.

\section{Experiments}

In this section, first, an automated fog generator is described, and then, experiments performed are provided.

\subsection{Automated Fog Generator (AFG)}

An experimental setup in the lab includes an automated fog generator (AFG), which sprays controlled fog amounts into the sampling volume of the laser particle size analyzer (LPSA). The $1 \times \mathrm{w} \times \mathrm{h}$ of the lab were $8 \mathrm{~m} \times 6 \mathrm{~m} \times 3 \mathrm{~m}$, respectively, which was selected to reduce dynamical effects, e.g., stability of air. The relative humidity with respect to water $(\mathrm{RH})$ and air temperature $\left(\mathrm{T}_{\mathrm{a}}\right)$ inside the lab were set up at about $63 \%$ and $25{ }^{\circ} \mathrm{C}$, respectively. This will create a near saturation environment when vapor flux into the lab increases. The AFG is able to generate fog with different chemical compositions, leading to variations in droplet sizes (d), number concentrations $\left(\mathrm{N}_{\mathrm{d}}\right)$, and liquid water content (LWC). It is designed to work with up to six different fluids with adjustable spraying amounts over durations of $0.2-5.5 \mathrm{~s}$. Switching between containers of agents is done via small valves. An important advantage of AFG is that it offers a fast and easy way to pulverize different chemical solutions and also allows a precise control of the amounts of aerosol impurities released into the fluids. 
Figure 1 shows the block diagram of the experimental setup. Important components of the system are shown with numbers overlaid on the figure. Nitrogen under pressure is fed from the gas pressure tank (8) to an atomizing nozzle (3), thus drawing liquid from one of the containers (6). Depending on the impurity (composition and amount of aerosols), the corresponding container is used for fog generation. The prototype has six branches with six controlling valves (5), so that switching between different containers is performed quickly and easily. A pulse generator (4) that is specially designed for the system controls the electromagnetic valve (2). Different settings can be selected to achieve specific durations of fog spraying. The control unit generates uniform impulses with a time step in the range of 0.2 to $5.5 \mathrm{~s}$. When the desired values for the impulse duration are set, the generation of an impulse is initiated mechanically. This impulse is transferred to the electromagnetic valve (2), and thus, a spraying through the nozzle with the desired duration is achieved. Fog produced by the nozzle is directed towards a laser particle size analyzer's sampling area to measure the artificially generated fogs' physical properties. The laser particle size analyzer (LPSA) is the Winner 319A model manufactured by Winner Particle Instrument Stock Co. Ltd., Jinan, China measuring particles between 1 and $500 \mu \mathrm{m}$ size range, with a distance of $2 \mathrm{~m}$ between the LPSA transmitter and receiver.

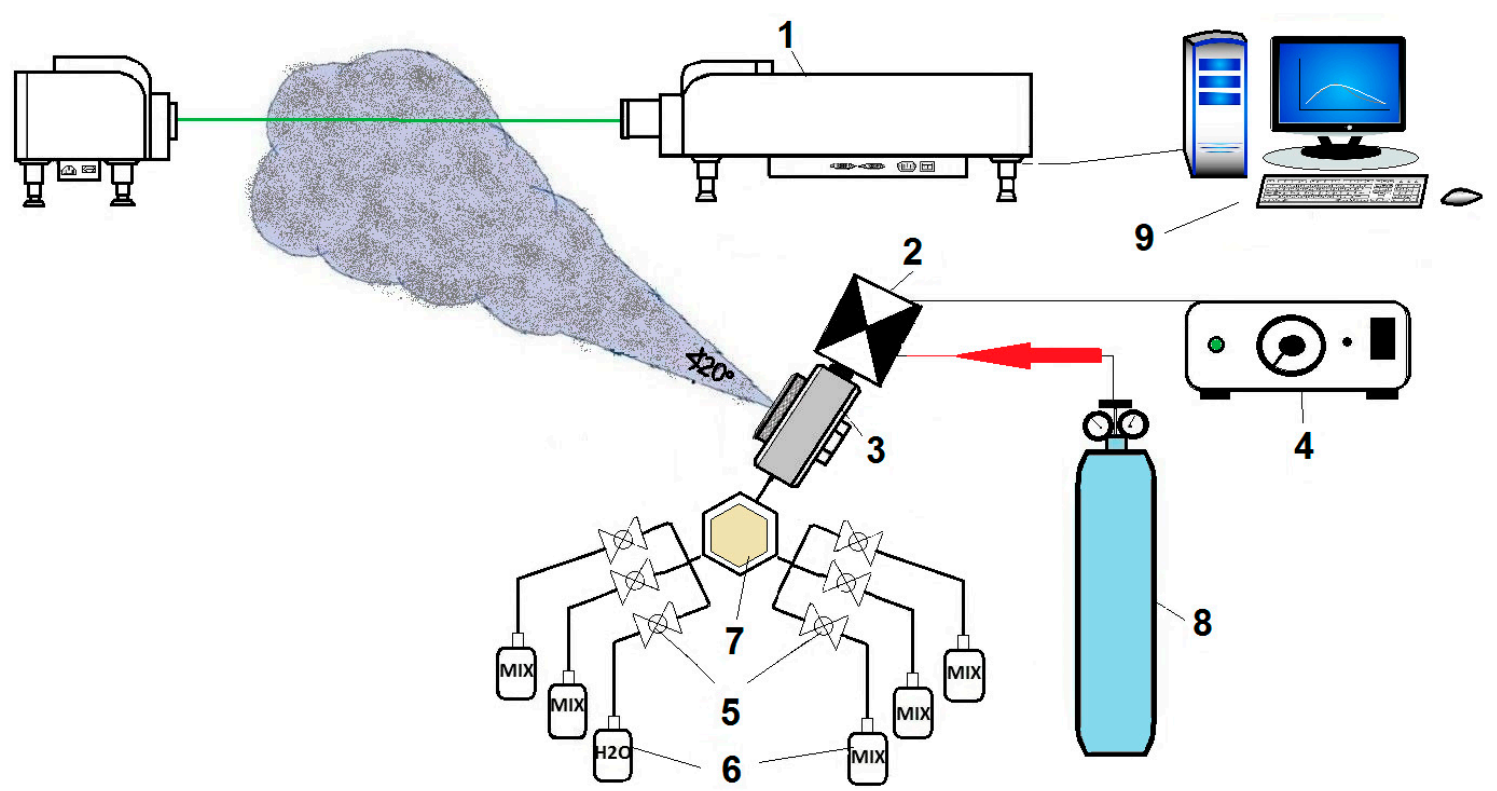

Figure 1. Block diagram of the automated system for the generation of fog with impurities. 1. Laser particle size analyzer, 2 . electromagnetic valve, 3. nozzle, 4. spray duration control unit, 5 . valves, 6. fluid containers, 7. mixing hub, 8. pressurized gas tank, and 9. PC for processing and visualizing the results.

\subsection{Experiments}

In the experiments, the four conditions are tested, and they are explained below.

Three kinds of chemicals were dissolved in distilled water, which are potassium dihydrogen phosphate- $\mathrm{KH}_{2} \mathrm{PO}_{4}$, urea- $\mathrm{CO}\left(\mathrm{NH}_{2}\right)_{2}$, and potassium hexacyanoferrate trihydrate- $\mathrm{K}_{3}\left(\mathrm{Fe}(\mathrm{CN})_{6}\right)$. These chemicals were chosen because they have characteristics similar to CBRN agents, but they are harmless. In such a way, the presence of dangerous pollutants in fog is simulated. For example, $\mathrm{KH}_{2} \mathrm{PO}_{4}$ has been selected as a harmless simulant of the CRBN agents used in chemical warfare with highly lethal $\mathrm{G}$ - and V-series of the nerve gas class. In a water solution, $\mathrm{KH}_{2} \mathrm{PO}_{4}$ dissociates to give phosphate ions that resemble the $C R B N$ molecular structure. The $\mathrm{K}_{3}\left(\mathrm{Fe}(\mathrm{CN})_{6}\right)$ is chosen as a chemical warfare agent simulant due to the presence of cyanide ions in its structure. They bond each other in a stable complex state with iron, which makes the compound safe to work with. The cyanide functional group is a constituent of blood agents such as cyanogen chloride and hydrogen cyanide. The prepared solutions 
were then pulverized using the automated system for fog modification. Pure distilled fog water is also measured and used for comparisons.

The experiments are designed to study how different impurities (chemical compounds) described above alter the spectral distribution of artificially generated fog particles that are composed of water vapor and chemical compounds at gas pressure (P) over $100 \mathrm{~s}(\mathrm{~T})$ equals to 2 bars with pulse duration of $5.5 \mathrm{~s}$. Four concentrations of each of the above mentioned compounds were dissolved in distilled water at a volume mixing level of $2.5 \%, 5 \%, 7.5 \%$, and $10 \%$. For all of the conducted experiments, measurements were taken at each second in a distance of $70 \mathrm{~cm}$ from the nozzle. The 100 measurements in each set are then averaged for each solution. The $\mathrm{T}_{\mathrm{a}}$ and $\mathrm{RH}$ were kept at $25^{\circ} \mathrm{C}$ and $63 \%$, respectively. These environmental conditions were monitored with thermometers and hygrometers that were controlled by air conditioners and moisture absorbers. The diameter of the nozzle is $0.4 \mathrm{~mm}$ with spraying angle of $20^{\circ}$ (suggested by the manufacturer company, Lechler $\mathrm{GmbH}$, Metzingen, Germany). The nozzle (model \#136.316.35.A2) is a pneumatic brass-plated atomizing nozzle, which works on the siphon/gravity principle. At $\mathrm{P}=2$ bar, the water volume flux of fog droplets emitted from the nozzle was $0.13 \mathrm{~L} \mathrm{~s}^{-1} \mathrm{~cm}^{-2}$.

Aerosols act as condensation nuclei for the formation of fog droplets. Some chemical components, such as the ones studied in this work, can lead to the modification of the fog droplet count and their growth rates through the effects of solute on vapor pressure when RH nears $100 \%$. Although a smaller mass of solutes acts as nuclei, the larger their size, the faster droplets will grow. A mixture of vapor and solute can also modify the vapor pressure over the solution, which can result in the growing of droplets slower or faster. This growth will strongly depend on $\mathrm{RH}$, which is a function of $e_{s}$ (saturated vapor pressure of a solution) and $e_{a}$ (environmental air vapor pressure). The molecular structure of the solution and its hygroscopicity also affects droplet growth.

\subsection{Method}

There are various aerosols in the atmosphere that act like hydrophilic (like water, i.e., solvent) and water-soluble ones (dissolved in water). The effect of soluble $\mathrm{CCN}$ can be important for the water evaporation (as solvent); therefore, curvature and solute effects can be considered for droplet growth. However, for small droplets, solute effects can be more critical for droplet growth or evaporation. With solute effects, the evaporation rate is lowered, resulting in condensation of the solvent. Then, the equilibrium water pressure $\left(e_{e}\right)$ will be less than the saturated one $\left(e_{s}\right)$ over flat water surfaces. When the amount of solute is increased, $e_{e}$ will decrease more, resulting in larger droplets. The evaporation rate of water molecules can be written as

$$
\gamma_{s}=\frac{n_{s}}{n_{w}+n_{s}} \sim \frac{n_{s}}{n_{t}}
$$

where $n_{w}, n_{s}$, and $n_{t}$ are the number of moles of water in a volume, number of moles of solute in the same volume, and the number of moles in the same volume for pure water, respectively. As a result, the evaporation rate from the water surface decreases, and this can be expressed as

$$
e_{m}=e_{s}\left(1-\gamma_{s}\right)
$$

where $e_{m}$ is the vapor pressure of the mixing (solution).

Then, the solute effect on vapor pressure of the solution (Raoult's Law) can be written as:

$$
\gamma_{s}=\frac{n_{s}}{n_{t}}=\frac{i N_{s}}{n_{t} V_{d}}=\frac{3 i N_{s}}{n_{t}\left(4 \pi r_{d}^{3}\right)}
$$

where $N_{s}$ is the total number of moles of the solute, $V_{d}$ is the droplet volume, $r_{d}$ is the droplet radius, and $i$ is the Van 't Hoff factor accounted for the splitting of solutes into components when they dissolve. Based on Equation (3), experimental results followed up a theory that increasing droplet size results in 
less $\gamma_{\mathrm{s}}$ but increasing $e_{m}$ near to $e_{s}$. On the other hand, increasing $N_{s}$ reduces vapor pressure of the mixture, which results in its faster growth. Clearly, when droplet sizes become smaller and solute mass increases, mixture-saturated vapor pressure becomes smaller, allowing droplets to grow faster and leading to an increased settling of the particles.

Large $N_{s}$ values and decreasing droplet volume (smaller radius) but increasing $n_{t}$ (number of moles per unit volume of pure water) can result in a larger denominator of Equation (3), although the total moles of solute increases (numerator, $N_{s}$ ). This means that lower vapor pressure will occur in the solution but droplets will be much smaller compared to ones obtained for smaller $n_{t}$ values. Therefore, growth of the droplets will be different as a function of $n_{t}$, and that will lead to smaller solution droplets in the air rather than ones falling to the surface. Results below provided should be considered in light of the conditions described here. In either way of the formation of smaller or larger droplets, increasing solutes can affect the life cycle of fog droplets (growth time).

\section{Results}

The results are provided for three chemical compounds, including potassium dihydrogen phosphate, urea, and potassium hexacyanoferrate trihydrate. Here, fog droplet spectra and calculated parameters representing tests performed for each compound are provided. In Figures 2-5, the double $y$-axes representing the cumulative (red line) and volumetric percentage (histogram) of the respective group versus particle diameter are provided. Results for each chemical component are given below.

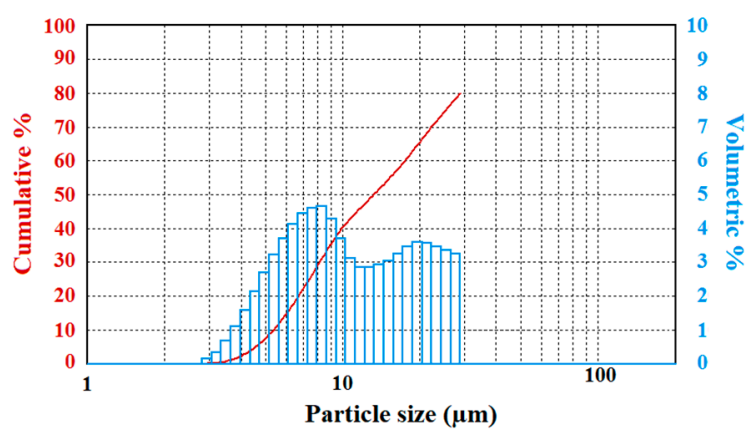

(a)

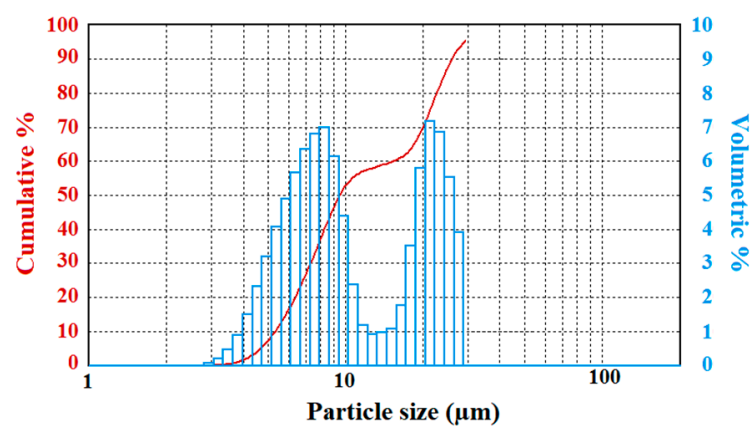

(c)

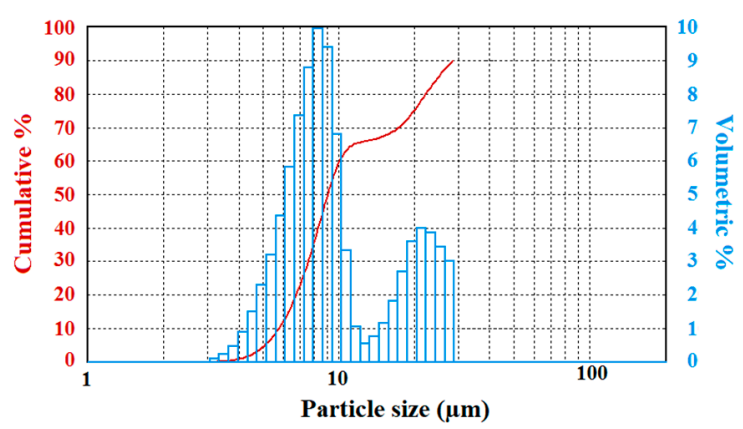

(b)

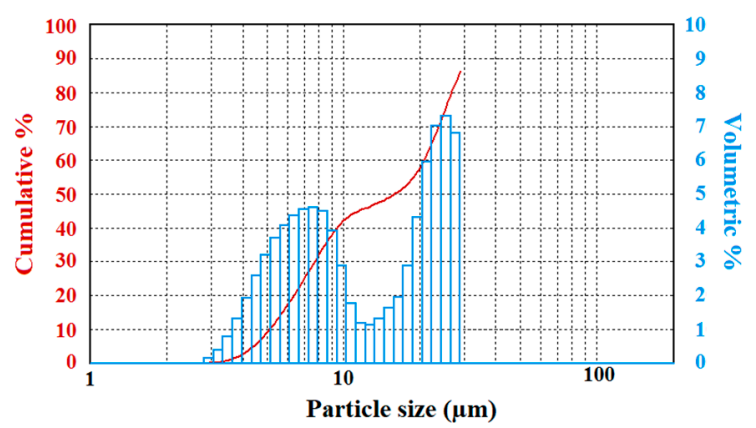

(d)

Figure 2. The $\%$ of solution contribution to fog spectral volume (right $y$-axis) and cumulative particle volume concentration (left $y$-axis) versus droplet diameter ( $x$-axis) are shown similarly in (a), (b), (c), and (d). Averaged fog droplet spectra below $30 \mu \mathrm{m}$ containing $2.5 \%, 5 \%, 7.5 \%$, and $10 \%$ of the amounts of dissolved urea (carbamide) are shown in $(\mathbf{a}),(\mathbf{b}),(\mathbf{c})$, and $(\mathbf{d})$, respectively. 


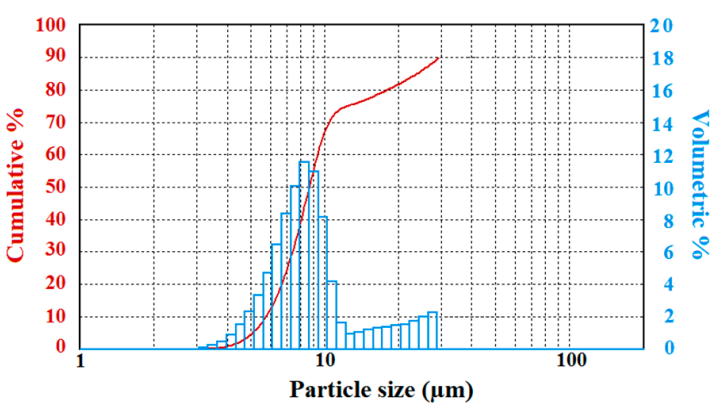

(a)

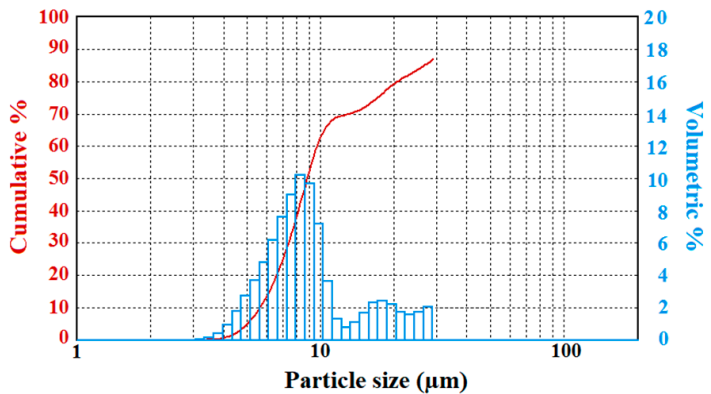

(c)

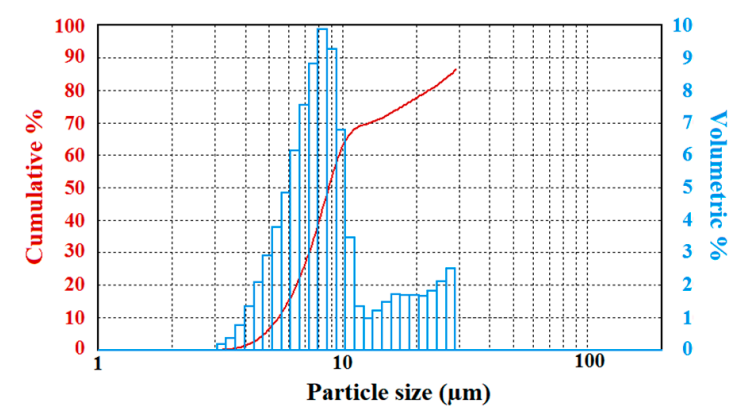

(b)

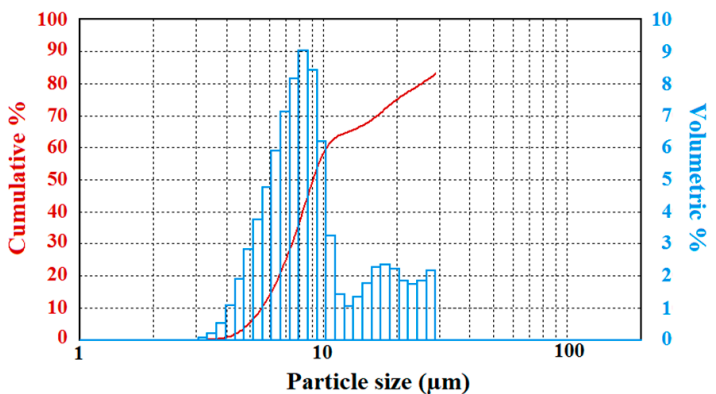

(d)

Figure 3. The $\%$ of solution contribution to fog spectral volume (right $y$-axis) and cumulative particle volume concentration (left $y$-axis) versus droplet diameter ( $x$-axis) are shown similarly in (a), (b), (c) and (d). Averaged fog droplet spectra below $30 \mu \mathrm{m}$ containing $2.5 \%, 5 \%, 7.5 \%$, and $10 \%$ of the amounts of potassium hexacyanoferrate trihydrate (PHT) are shown in (a), (b), (c), and (d), respectively.

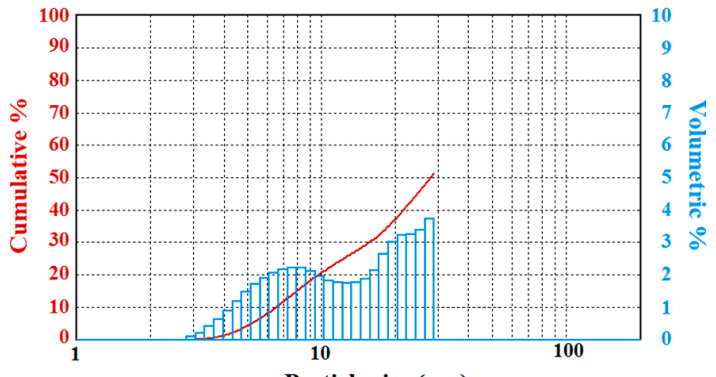

Particle size $(\mu \mathrm{m})$

(a)

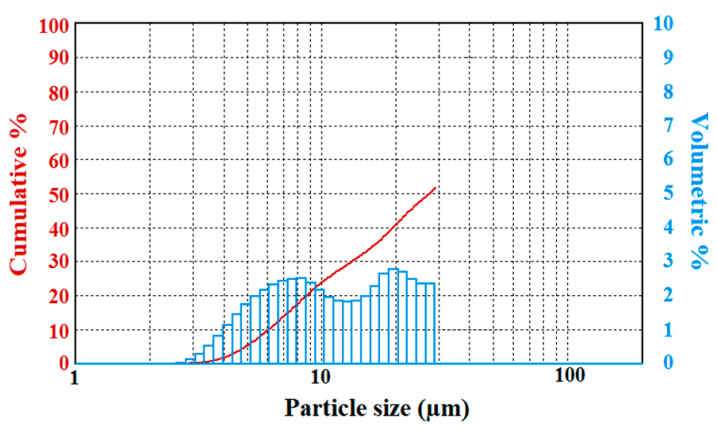

(c)

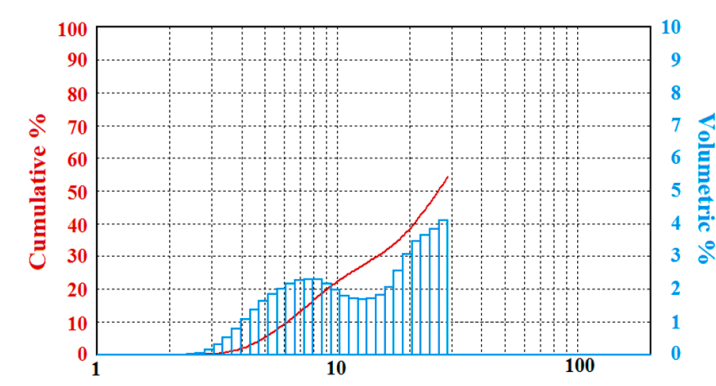

Particle size $(\mu \mathrm{m})$

(b)

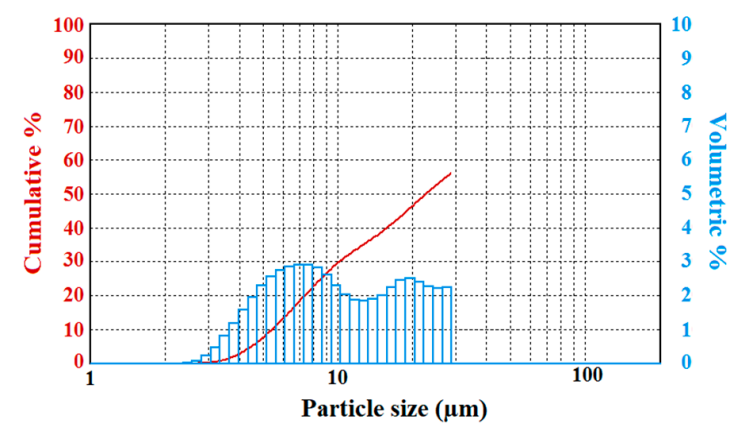

(d)

Figure 4. The $\%$ of solution contribution to fog spectral volume (right $y$-axis) and cumulative particle volume concentration (left $y$-axis) versus droplet diameter ( $x$-axis) are shown similarly in (a), (b), (c), and (d). Averaged fog droplet spectra below $30 \mu \mathrm{m}$ containing $2.5 \%, 5 \%, 7.5 \%$, and $10 \%$ of the amounts of potassium dihydrogen phosphate (PDP) are shown in (a), (b), (c), and (d), respectively. 


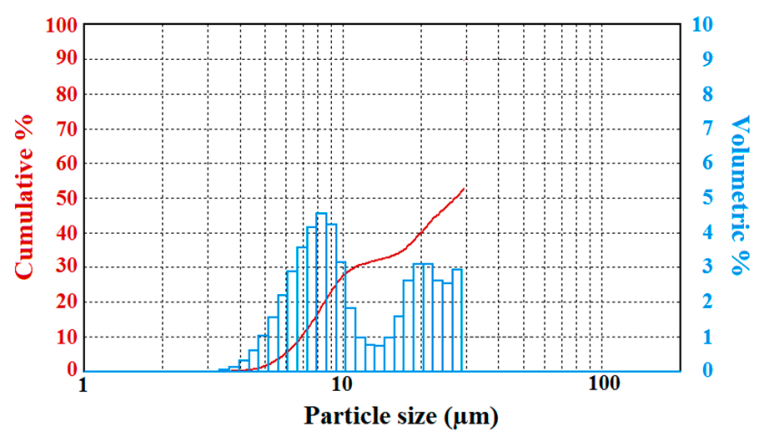

Figure 5. Averaged fog droplet spectrum below $30 \mu \mathrm{m}$ were obtained for the pure distilled water case with the $\%$ of solution contribution $\left(\mathrm{V}_{\mathrm{dt}}\right)$ to fog spectral volume (right $y$-axis) and cumulative particle volume concentration (left $y$-axis).

\subsection{Using Urea (Carbamide)}

In this experiment, results obtained from the LPSA are provided in Figure 2. Cumulative distribution values are shown on the left $y$-axis, and the percentage of solution contribution to fog spectral volume is given in right $y$-axis, for varying amounts of dissolved urea (carbamide) generated by the automated pulverizing system.

The solution containing $2.5 \%$ of urea produced droplets with a size distribution having two peaks (bimodal) at 8 and $20-\mu \mathrm{m}$ diameters. Assuming that fog droplet sizes are less than $30 \mu \mathrm{m}$, the cumulative contribution of fog droplet volume concentration $\left(\mathrm{V}_{\mathrm{dt}}\right)$ was at $82 \%$, but it was at $40 \%$ at sizes $<10 \mu \mathrm{m}$. At the $5 \%$ of urea, generated droplets had also a sharp bimodal distribution, with peaks at 8 and $20-\mu \mathrm{m}$ diameters. $\mathrm{V}_{\mathrm{dt}}$ was $92 \%$ at $10 \mu \mathrm{m}$ and $75 \%$ at sizes $<30 \mu \mathrm{m}$. Increasing the amount of dissolved urea resulted in more sharp peaks in bimodal distributions of the fog droplets. For the solution containing $7.5 \%$ of urea, $\mathrm{V}_{\mathrm{dt}}$ was $53 \%$ at $10 \mu \mathrm{m}$ and $97 \%$ at sizes $<30 \mu \mathrm{m}$. At the $10 \%$ of urea, spectra had peaks at 7.5 and $26-\mu \mathrm{m}$ diameters, and $V_{\mathrm{dt}}$ was $42 \%$ at diameters $<10 \mu \mathrm{m}$. It had $90 \%$ for diameters less than $30 \mu \mathrm{m}$.

Overall, the urea solutions produced droplet spectra with bimodal peaks from 3- $\mu \mathrm{m}$ up to $30-\mu \mathrm{m}$ diameters. Note that fog droplets usually have size ranges from $1 \mu \mathrm{m}$ up to $20-30 \mu \mathrm{m}$ [16]. For sizes greater than $30 \mu \mathrm{m}$, fog droplets may be drizzling out from the fog layer [17]. $\mathrm{V}_{\mathrm{dt}}$ was found to be $82 \%$, $92 \%, 97 \%$, and $90 \%$ in Figure $2 a-d$, respectively, which represents mainly fog droplets. With having 5\% of urea dissolved in the distilled water, the percentage of droplets occurring for sizes $<10 \mu \mathrm{m}$ is found to be the greatest among all measured sizes. Another point is that increasing the concentration of urea from $5 \%$ to $7.5 \%$ led to a decrease in $\mathrm{V}_{\mathrm{dt}}$ for sizes $<10 \mu \mathrm{m}$ and an increase in $\mathrm{V}_{\mathrm{dt}}$ for sizes $>20 \mu \mathrm{m}$. Further increasing of urea to $10 \%$ led to a significant decrease in droplet counts for sizes $<10 \mu \mathrm{m}$ but resulted in an increase of droplet counts for diameters $>30 \mu \mathrm{m}$.

\subsection{Using Potassium Hexacyanoferrate Trihydrate (PHT)}

In this experiment, analysis is done similar to Section 3.1. Results are provided in Figure 3. These measurements were also obtained using the LPSA. The results are shown for varying amounts of dissolved potassium hexacyanoferrate trihydrate (PHT) also generated by the automated pulverizing system.

The solutions containing $2.5 \%, 5 \%, 7.5 \%$, and $10 \%$ of PHT used to generate fog droplet spectra are shown in Figure 3a-d, respectively. Figures show double or multiple peaks at diameters greater than $8 \mu \mathrm{m}$. Assuming that fog droplet diameters are $<30 \mu \mathrm{m}, \mathrm{V}_{\mathrm{dt}}$ for the $2.5 \%$ solution was estimated at $90 \%$. It was at $67 \%$ for diameters $<10 \mu \mathrm{m}$ (Figure 3a). At the $5 \%$ of PHT, generated droplets had a sharp bimodal distribution, with peaks at 9 and $30 \mu \mathrm{m}$. $\mathrm{V}_{\mathrm{dt}}$ was $65 \%$ at $10 \mu \mathrm{m}$ and $88 \%$ at sizes $<30 \mu \mathrm{m}$ (Figure $3 b$ ). Only $12 \%$ of $\mathrm{V}_{\mathrm{dt}}$ was found at diameters greater than $30 \mu \mathrm{m}$. The solution containing $7.5 \%$ (Figure 3c) generated droplets with three-modal spectra with peaks at 8, 20, and $30 \mu \mathrm{m}$. In this case, 
$\mathrm{V}_{\mathrm{dt}}$ was $60 \%$ at $10 \mu \mathrm{m}$ and $88 \%$ at sizes $<30 \mu \mathrm{m}$. The solution with $10 \%$ (Figure $3 \mathrm{~d}$ ) generated multiple peaks at diameters of 8,17 , and $30 \mu \mathrm{m}$. $\mathrm{V}_{\mathrm{dt}}$ was at $60 \%$ at sizes $<10 \mu \mathrm{m}$ and $88 \%$ for sizes $<30 \mu \mathrm{m}$.

Overall, all of the PHT solutions generated droplet spectra with both bimodal and multiple peaks from $3 \mu \mathrm{m}$ up to $30 \mu \mathrm{m}$. $V_{\mathrm{dt}}$ for sizes less than $30 \mu \mathrm{m}$ was $90 \%, 88 \%, 88 \%$, and $85 \%$ in Figure $3 \mathrm{a}-\mathrm{d}$, respectively. This means that droplet sizes generated were representative of fog droplets' microphysical properties. With having $5 \%$ of PHT dissolved in distilled water, the $V_{\mathrm{dt}}$ for sizes $<10 \mu \mathrm{m}$ was the highest among all the experiments. This result was similar to the Section 3.1 analysis. It is also found that increasing the volume concentration of PHT from $2.5 \%$ to $10 \%$ led to an increase of $\mathrm{V}_{\mathrm{dt}}$ up to $5 \%$ when diameters $>30 \mu \mathrm{m}$.

\subsection{Using Potassium Dihydrogen Phosphate (PDP)}

In this experiment, results are shown in Figure 4 using PDP solute. The solutions containing 2.5\%, $5 \%, 7.5 \%$, and $10 \%$ of PDP were used to generate fog droplet spectra that are shown in Figure $4 a-d$, respectively. The generated droplets had double peaks at sizes greater than $8 \mu \mathrm{m}$. Assuming that fog droplet diameters are usually less than $30 \mu \mathrm{m}$, total $\mathrm{V}_{\mathrm{dt}}$ in Figure $4 \mathrm{a}$ is found at about $53 \%$ at sizes $<30 \mu \mathrm{m}$. The solution containing $2.5 \%$ and $5 \%$ of PDP generated a sharp bimodal distribution with $\mathrm{V}_{\mathrm{dt}}$ $\sim 20 \%$ at $10 \mu \mathrm{m}$ and $\sim 55 \%$ at sizes $<30 \mu \mathrm{m}$. The solution containing $7.5 \%$ of PDP (Figure $4 \mathrm{c}$ ) generated a bimodal distribution with peaks at $8-\mu \mathrm{m}$ and $20-\mu \mathrm{m}$ diameters. In this case, $\mathrm{V}_{\mathrm{dt}}$ was $25 \%$ and $52 \%$ at $10 \mu \mathrm{m}$ and at sizes $<30 \mu \mathrm{m}$, correspondingly. The solution with $10 \%$ of PDP generated droplet spectra with two peaks at 7 and $20 \mu \mathrm{m}$, and $\mathrm{V}_{\mathrm{dt}}$ was found to be $57 \%$ at sizes $<30 \mu \mathrm{m}$.

Overall, all of the PDP solutions generated droplet spectra with bimodal diameter distributions from $3 \mu \mathrm{m}$ up to $30 \mu \mathrm{m}$ when solution was less than $5 \%$. $\mathrm{V}_{\mathrm{dt}}$ corresponding to fog droplet size of $30 \mu \mathrm{m}$ was $53 \%, 58 \%, 52 \%$, and $57 \%$ in Figure $4 a-d$, respectively. When having $2.5 \%$ and $5 \%$ of PDP dissolved in the distilled water, the percentage of droplets occurring for sizes $>10 \mu \mathrm{m}$ is the greatest among all the solutions. Increasing the concentration of PDP from $2.5 \%$ to $10 \%$ resulted in an increase in $V_{\mathrm{dt}}$ for diameters $<10 \mu \mathrm{m}$ and a decrease in $\mathrm{V}_{\mathrm{dt}}$ for diameters $>20 \mu \mathrm{m}$.

\subsection{Spectrum of Pure Distilled Fog Droplets}

The spectrum of pure fog droplets is provided here as a reference for comparison purposes. Figure 5 shows the results without including any chemical solute. Results suggest that pure distilled fog droplets had multiple peaks at $8 \mu \mathrm{m}, 20 \mu \mathrm{m}$, and $30 \mu \mathrm{m}$. The smallest measured droplets sizes are found at diameters around $3 \mu \mathrm{m}$. Forty-eight percent of $V_{d t}$ was found at sizes greater than $30 \mu \mathrm{m}$. Results suggested that the nozzle used for fog droplet generation was likely accurate. Various solution amounts generated results similar to real fog conditions, as seen in Figure 5.

A decrease of droplet counts at various sizes likely occurs because of reduced RH beyond the fog volume. In fact, small droplets will evaporate faster than large ones when RH just below $=100 \%$. Therefore, reduction of droplets at larger size ranges can occur due to droplet settling being related to droplet size.

\section{Discussion}

Results suggest that fog droplet spectra generated with the pure water case were found similar to real fog measurements collected in field projects [16,18-20]. These studies showed that fog droplet spectra had sizes from a few microns up to $30 \mu \mathrm{m}$, but occasionally, they reach up to $40-50 \mu \mathrm{m}$. When sizes get larger than 30 microns, fog droplets can settle down onto surfaces, reducing droplet counts in the air.

Nucleation characteristics of the chemicals used in solutions play an important role as cloud condensation nuclei $(\mathrm{CCN})$ in the natural environments, and they can be controlled by lab set-up conditions. Then, the mixture of the vapor and $\mathrm{CCN}$ results in fog droplets, either by the internal mixing of vapor and solute or by direct condensation. Washing out chemical substances from the air sprayed as CBRN elements, after which particles grow faster than under regular fog conditions, 
results in the cleaning of atmospheric air parcels. These conditions can be modified by increasing the saturation $(\mathrm{RH})$ and $\mathrm{T}$, cooling rate, $\mathrm{CCN}$, and dynamics of the environment.

Life cycles of fog droplets can be strongly related to lab physical set-up conditions, e.g., its volume and height, as well as to thermodynamic parameters of the environment, such as $\mathrm{T}$ and $\mathrm{RH}$. Therefore, thermodynamic conditions similar to real fog environment conditions should be adapted for the tests. During the experiments, wetness at the surface was not observed, indicating that the physical body of the lab was not affecting our results. However, lower RH and higher $\mathrm{T}$ can result in much faster dissipation of the foggy conditions. Therefore, experiments in the future need to be further repeated at various thermodynamical conditions near the saturation levels rather than at low RH values. In the analysis, the generation of droplets using various chemical compounds was not easy because of the control of thermodynamic conditions in the lab, such as relative humidity $\mathrm{RH}$ and air temperature $\mathrm{T}_{\mathrm{a}}$. The use of pure distilled water in fact was important to validate the changes of chemical compounds and their impact on the fog microphysical structure. The most difficult issue was the measurement of droplet spectra without a fog spectral probe; therefore, we could not estimate the exact value of total droplet volume concentration $\left(\mathrm{V}_{\mathrm{t}}\right)$ but only the $\%$ value of $\mathrm{V}_{\mathrm{t}}$ was obtained. This was the most difficult issue; in the future, a fog spectral device is planned to be used in characterizing details of the microphysics of fog spectra with various chemical compounds.

Latest studies [21-24] suggested that chemical components of aerosols could play an important role for $\mathrm{CCN}$ concentration. For example, $\mathrm{NaCl}$ (sea salt) particles are a good source of $\mathrm{CCN}$ [25]; increasing their number concentration and size as a function of turbulence can enlarge/narrow the droplet spectra, resulting in larger/smaller fog droplet sizes (see last paragraph in Section 3). The work of Woodcock (1978) showed that salt particles, similar to the ones studied here, can significantly change droplet spectra and $\mathrm{N}_{\mathrm{t}}$. Therefore, the results of this work can be used to reduce CRBN concentrations that impact on the environment and human life during peace and war times. However, the results are obtained at lower RH values, which needs to be researched further near saturation levels.

Table 1 shows the mean diameters of fog droplets for the entire size range, as well as for sizes $<30 \mu \mathrm{m}$ and $>30 \mu \mathrm{m}$ of the pulverized solutions at 2 bar of gas pressure, which were measured by the LPSA. The results suggest that the solutions resulted in various mean values of droplet diameters depending on the solution type and volume ratio, and that may be used for the cleaning of CRBN agents from the environment.

Table 1. Summarized results for the average diameters of fog droplets of the pulverized solutions.

\begin{tabular}{|c|c|c|c|}
\hline Pulverized Solution & 0-100 $\mu \mathrm{m}$ Mean & Size $<30 \mu \mathrm{m}$ Mean & Size $>30 \mu \mathrm{m}$ Mean \\
\hline Distilled water & 28.6 & 13.7 & 47.4 \\
\hline Distilled water $+2.5 \%$ urea (carbamide) & 18.7 & 12.9 & 45.8 \\
\hline Distilled water $+5 \%$ urea (carbamide) & 13.7 & 12.0 & 37.2 \\
\hline Distilled water $+7.5 \%$ urea (carbamide) & 14.0 & 13.5 & 35.1 \\
\hline Distilled water $+10 \%$ urea (carbamide) & 16.9 & 14.7 & 36.5 \\
\hline $\begin{array}{l}\text { Distilled water }+2.5 \% \text { potassium } \\
\text { hexacyanoferrate trihydrate }\end{array}$ & 12.6 & 10.4 & 37.7 \\
\hline $\begin{array}{l}\text { Distilled water }+5 \% \text { potassium } \\
\text { hexacyanoferrate trihydrate }\end{array}$ & 13.8 & 10.6 & 38.5 \\
\hline $\begin{array}{l}\text { Distilled water }+7.5 \% \text { potassium } \\
\text { hexacyanoferrate trihydrate }\end{array}$ & 14.3 & 10.6 & 43.7 \\
\hline $\begin{array}{l}\text { Distilled water }+10 \% \text { potassium } \\
\text { hexacyanoferrate trihydrate }\end{array}$ & 17.0 & 10.8 & 52.0 \\
\hline $\begin{array}{l}\text { Distilled water }+2.5 \% \text { potassium } \\
\text { dihydrogen phosphate }\end{array}$ & 30.6 & 14.9 & 50.1 \\
\hline $\begin{array}{l}\text { Distilled water }+5 \% \text { potassium } \\
\text { dihydrogen phosphate }\end{array}$ & 30.5 & 14.9 & 52.0 \\
\hline $\begin{array}{l}\text { Distilled water }+7.5 \% \text { potassium } \\
\text { dihydrogen phosphate }\end{array}$ & 33.9 & 13.5 & 58.6 \\
\hline $\begin{array}{l}\text { Distilled water }+10 \% \text { potassium } \\
\text { dihydrogen phosphate }\end{array}$ & 35.7 & 12.5 & 69.2 \\
\hline
\end{tabular}


Table 1 shows that the addition of up to $10 \%$ of potassium dihydrogen phosphate to distilled water leads to an increase of the average diameter of the droplets, compared to those of pure distilled water. The lower concentrations of solution $(2.5 \%$ and $5 \%)$ led to a significant increase $(\sim 8 \%)$ in the average diameter of droplets. A concentration of $7.5 \%$ (10\%) of this impurity led to a decrease of about $2 \%(9 \%)$ of the average diameter of the generated fog droplets.

The addition of urea to distilled water resulted in a decrease of the average diameter of the droplets compared to the case when the solution is pulverized from pure distilled water. The presence of $2.5 \%$ of urea in the water volume resulted in a decrease in the average diameter of droplets by $6 \%$. The concentration of urea at $5 \%$ and $7.5 \%$ resulted in a decrease in the average diameter of droplets by $13 \%$ and $2 \%$, respectively, and with the highest concentration of solution used as $10 \%$, led to an increase in the average diameter of fog droplets by $7 \%$. Note that the number of moles given in Equation (3) can play an important role on the final results related to droplet sizes and number concentrations, which depend on the mixing characteristics of solutes with pure water.

When introducing various concentrations of potassium hexacyanoferrate trihydrate to distilled water, the average diameter of droplets decreased significantly. As explained previously, this can be due to increasing the total number of moles (with smaller droplets). At the lowest concentration of $2.5 \%$, the diameter of fog droplets decreased by $25 \%$. For the solutions containing $5 \%$ and $7.5 \%$ of this chemical, the droplets are about $23 \%$ smaller, and for the highest concentration of $10 \%$, about $21 \%$ smaller. The higher the concentration of potassium hexacyanoferrate trihydrate, the weaker the decrease of the average diameter of fog droplets.

The results of this work need to be evaluated further in more controlled environments and test the microphysics of fog in polluted environments with various chemical components. Additional information for thermodynamics and dynamics of the environment can also have an impact on fog droplet spectra [26-32]; therefore, results need to be also tested during field projects under various meteorological conditions.

As pointed out, this work was an experimental work performed in a lab; therefore, the experiments should be further performed during field projects. In fact, the analysis performed in this work is similar to many wind tunnel and cloud chamber studies and faces similar concerns for the results.

\section{Conclusions}

This work uses a fog generating system and various chemical components in a solution to study the size distribution of artificially generated fog droplets. These solutions included changing volume concentrations and types of chemical impurities, including PDH, PDP, and carbamide. These chemicals resemble CRBN agents that are extensively used in warfare.

This work helps to develop new methods on how fog microphysical parameters change with the addition of chemical compounds in the pulverized solutions.

The main conclusions can be summarized as:

- Artificially generated fog droplet spectra, leading to higher settling rates, can be used to reduce the amount of dangerous chemical compounds found in the air, such as CBRNs.

- Increasing sizes of droplets can depend on both thermodynamic and dynamic conditions, as well as on the chemical structures of the compounds; these include solute amount and RH, as well as T.

- Increasing the volume of chemical compounds usually resulted in increasing droplet mean size and multiple peaks, indicating the settling of chemical compounds through fog development into larger sizes, but evaporation was also possible.

- The artificial fog generating system used can also be further developed to test the impact of various aerosol chemical properties on fog formation and modified into a compact prototype system.

In the future, the results obtained from this study will be used further to develop a better fog generating system that can also be used in the field. Field tests would be very important when fog can be used as a cleaning agent of contaminations of public sites and environments, and this may 
occur due to various reasons, such as terrorist attacks with CBRN agents, military actions, industrial accidents, and environmental disasters.

Author Contributions: Methodology, O.I. and I.G.; formal analysis P.T. and I.G.; investigation, P.T. and O.I.; writing-original draft preparation, O.I. and P.T.; and writing-review and editing, I.G. All authors have read and agreed to the published version of the manuscript.

Funding: This work has been funded by the FP7-SEC-2012-1 program of the EU Commission under grant number 312804 and partially supported by the Bulgarian Ministry of Education and Science under the National Research Programme "Young scientists and postdoctoral students" approved by DCM \# 577 / 17.08.2018.

Conflicts of Interest: The authors declare no conflict of interest.

\section{References}

1. Yang, D.; Ritchie, H.; Desjardins, S.; Pearson, G.; MacAfee, A.; Gultepe, I. High resolution GEM-LAM application in marine fog prediction: Evaluation and diagnosis. Weather Forecast. 2009, 25, 727-748. [CrossRef]

2. Gultepe, I.; Tardif, R.; Michaelides, S.C.; Cermak, J.; Bott, A.; Bendix, J.; Müller, M.D.; Pagowski, M.; Hansen, B.; Ellrod, G.; et al. Fog research: A review of past achievements and future perspectives. Pure Appl. Geophys. 2007, 164, 1121-1159. [CrossRef]

3. Dumont, E.; Cavallo, V. Extended photometric model of fog effects on road vision. J. Transp. Res. Board 2004, 1862, 77-81. [CrossRef]

4. Torregrosa, A.; O'Brien, T.; Faloona, I. Coastal fog, climate change, and the environment. Eos Trans. Am. Geophys. Union 2014, 95, 473-474. [CrossRef]

5. Hackney, J.D.; Linn, W.S.; Avol, E.L. Potential risks to human respiratory health from "acid fog": Evidence from experimental studies of volunteers. Environ. Health Perspect. 1985, 63, 57-61. [CrossRef]

6. Liu, Z.; Kim, A.K. A review of water mist fire suppression systems-Fundamental studies. J. Fire Prot. Eng. 2000, 10, 32-50.

7. Doss, B.D. Comparison of fog irrigation with surface irrigation in corn production. Agron. J. 1974, 66, 105-107. [CrossRef]

8. Gultepe, I.; Isaac, G.A.; Strawbridge, K. Variability of cloud microphysical and optical parameters obtained from aircraft and satellite remote sensing during RACE. Inter. J. Climatol. 2001, 21, 507-525. [CrossRef]

9. Pilat, M.J.; Jaasund, S.A.; Sparks, L.E. Collection of aerosol particles by electrostatic droplet spray scrubbers. Environ. Sci. Technol. 1974, 8, 360-362. [CrossRef]

10. Perez-Diaz, J.L.; Qin, Y.; Ivanov, O.; Quinones, J.; Stengl, V.; Nylander, K.; Hornig, W.; Álvarez, J.; Ruiz-Navas, E.M.; Manzanec, K. Fast response CBRN high-scale decontamination system: COUNTERFOG: Science as the first countermeasure for CBRNE and cyber threats. In Enhancing CBRNE Safety \& Security; Malizia, A., D'Arienzo, M., Eds.; Springer: New York, NY, USA, 2017; pp. 61-69.

11. Ivanov, O.; Karatodorov, S.; Pérez-Díaz, J.L. Novel electromagnetic sensor for contaminations in fog based on the laser-induced charge effect. 2017 IEEE Sens. Proc. 2017, 1, 1509-1511.

12. Ivanov, O.; Kuneva, M. Quality control methods based on electromagnetic field-matter interactions. In Application and Experience of Quality Control; Ivanov, O., Ed.; INTECH: Vienna, Austria, 2011; pp. 509-536.

13. Todorov, P.; Ivanov, O.; Pashev, K.; Ralev, Y.; Pérez-Díaz, J.L. Automated 2D laser scanning systems for investigation of solid surfaces. Mach. Technol. Mater. 2019, 13, 306-309.

14. Ivanov, O.; Ralev, Y.; Todorov, P.; Popov, I.; Perez-Diaz, J.L.; Kuneva, M. System for generation of fogs with controlled impurities. Bulg. Chem. Commun. 2018, 50, 94-99.

15. Ivanov, O.; Ralev, Y.; Todorov, P.; Popov, I.; Angelov, K.; Perez-Diaz, J.L.; Kuneva, M. Laboratory system for artificial fog generation with controlled number and size distribution of droplets. Bulg. Chem. Commun. 2018, 50, 89-93.

16. Gultepe, I.; Pearson, G.; Milbrandt, J.A.; Hansen, B.; Platnick, S.; Taylor, P.; Gordon, M.; Oakley, J.P;; Cober, S.G. The fog remote sensing and modeling (FRAM) field project. Bull. Am. Meteorol. Soc. 2009, 90, 341-359. [CrossRef]

17. Gultepe, I.; Pavolonis, M.; Zhou, B.; Ware, R.; Burrows, W.; Garand, L. Freezing Fog and Drizzle Observations. In Proceedings of the SAE International Conference on Icing of Aircraft, Engines, and Structures, Prague, Czech Republic, 22-25 June 2015; SAE Technical Paper 2015-01-2113. SAE International: Warrendale, PA, USA, 2015. [CrossRef] 
18. Gultepe, I.; Fernando, H.J.S.; Pardyjak, E.R.; Hoch, S.W.; Silver, Z.; Creegan, E.; Hang, C. An overview of the MATERHORN fog project: Observations and predictability. Pure Appl. Geophys. 2016, 173, 2983-3010. [CrossRef]

19. Haeffelin, M.; Bergot, T.; Elias, T.; Tardif, R.; Carrer, D.; Chazette, P.; Colomb, M.; Drobinski, P.; Dupont, E.; Dupont, J.-C.; et al. PARISFOG: Shedding new light on fog physical processes. Bull. Am. Meteorol. Soc. 2010, 91, 767-783. [CrossRef]

20. Price, J.D.; Lane, S.; Boutle, I.A.; Smith, D.K.; Bergot, T.; Lac, C.; Duconge, L.; McGregor, J.; Kerr-Munslow, A.; Pickering, M.; et al. LANFEX: A field and modeling study to improve our understanding and forecasting of radiation fog. Bull. Am. Meteorol. Soc. 2018, 99, 2061-2077. [CrossRef]

21. Green, M.C.; Chow, J.C.; Watson, J.G.; Dick, K.; Inouye, D. Effects of snow cover and atmospheric stability on winter $\mathrm{PM}_{2.5}$ concentrations in western U.S. valleys. J. Appl. Meteorol. Climatol. 2015, 54, 1191-1201. [CrossRef]

22. Russell, L.M.; Sorooshian, A.; Seinfeld, J.H.; Albrecht, B.A.; Nenes, A.; Ahlm, L.; Chen, Y.; Coggon, M.; Craven, J.S.; Flagan, R.C.; et al. Eastern pacific emitted aerosol cloud experiment. Bull. Am. Meteorol. Soc. 2013, 94, 709-729. [CrossRef]

23. Shantz, N.C.; Gultepe, I.; Andrews, E.; Zelenyuk, A.; Earle, M.E.; Macdonald, A.M.; Liu, P.S.K.; Leaitch, W.R. Optical, physical, and chemical properties of springtime aerosol over Barrow Alaska in 2008. Int. J. Climatol. 2014, 34, 3125-3138. [CrossRef]

24. Junkermann, W.; Hacker, J.M. Ultrafine particles in the lower troposphere: Major sources, invisible plumes, and meteorological transport processes. Bull. Am. Meteorol. Soc. 2018, 99, 2587-2602. [CrossRef]

25. Woodcock, A.H. Marine fog droplets and salt nuclei-Part I. J. Atmos. Sci. 1978, 35, 657-664. [CrossRef]

26. Twomey, S. The nuclei of natural cloud formation part II: The supersaturation in natural clouds and the variation of cloud droplet concentration. Geofis. Pura Appl. 1959, 43, 243. [CrossRef]

27. Gultepe, I.; Isaac, G.A. The relationship between cloud droplet and aerosol number concentrations for climate models. Int. J. Climatol. 1996, 16, 941-946. [CrossRef]

28. Gultepe, I.; Isaac, G.A. Scale effects on averaging of cloud droplet and aerosol number concentrations: Observations and models. J. Clim. 1999, 12, 1268-1279. [CrossRef]

29. Cohard, J.; Pinty, J.; Bedos, C. extending twomey's analytical estimate of nucleated cloud droplet concentrations from CCN spectra. J. Atmos. Sci. 1998, 55, 3348-3357. [CrossRef]

30. Ghan, S.J.; Chuang, C.C.; Penner, J.E. A parameterization of cloud droplet nucleation, Part I.; Single aerosol species. Atmos. Res. 1993, 30, 197-222. [CrossRef]

31. Ghan, S.J.; Chuang, C.C.; Easter, R.C.; Penner, J.E. A parameterization of cloud droplet nucleation, Part I.I.; Multiple aerosol types. Atmos. Res. 1995, 36, 39-54. [CrossRef]

32. Chen, S.; Bartello, P.; Yau, M.K.; Vaillancourt, P.A.; Zwijsen, K. Cloud droplet collisions in turbulent environment: Collision statistics and parameterization. J. Atmos. Sci. 2016, 73, 621-636. [CrossRef] 